Meta

Journal des traducteurs

Translators' Journal

\title{
Applications of the Language Laboratory to Training in Simultaneous Interpretation
}

\section{Craig Chapman}

Volume 22, numéro 4, décembre 1977

URI : https://id.erudit.org/iderudit/002218ar

DOI : https://doi.org/10.7202/002218ar

Aller au sommaire du numéro

Éditeur(s)

Les Presses de l'Université de Montréal

ISSN

0026-0452 (imprimé)

1492-1421 (numérique)

Découvrir la revue

Citer cet article

Chapman, C. (1977). Applications of the Language Laboratory to Training in

Simultaneous Interpretation. Meta, 22(4), 264-269.

https://doi.org/10.7202/002218ar d'utilisation que vous pouvez consulter en ligne. 


\section{Applications \\ of the Language Laboratory \\ to Training \\ in Simultaneous Interpretation}

A major drawback in attempting to teach simultaneous interpretation in most academic settings is the lack of suitable electronic equipment and simulated conference facilities such as those used by the major AIIC - accredited schools in Europe and America.

We have demonstrated experimentally that a conventional language laboratory may be successfully adapted to training in simultaneous interpretation. Although optimal simulation of conference conditions is clearly impossible - due principally to the lack of wired auditorium, fully wired interpreter booths, sound engineer's console and electronic relays for several languages - it is still feasible to provide adequate, supervised training for a substantial number of trainees working in different combinations. By a skillful use of tapes and live utterances, the instructor can successfully monitor and supervise at least three target languages and three source languages during a single class section. To do this, he must be a trained interpreter, have appropriate skills in the relevant languages, and have the assistance of competent technical personnel.

The following applications are proposed :

\section{APPLICATION 1}

\section{Functional Description}

Instructor or speaker(s) speak through the console microphone to students in student positions spaced at least one position apart with different target languages in alternating rows. Students interpret simultaneously to dead microphones.

\section{Technical Description}

Most elementary, high school, and college labs built during the 60 's have a wide variety of communications functions built into the Instructor Console and the student positions. The primary mode is that of instructor to student, and operates 
both live voice and recorded tape. It is this function which is used here. Different languages (pre-recorded tapes) can also be placed on the master console tape decks ; student positions are switched according to the desired \& input $\$$ language (e.g. channel 1 : French, channel 2 : Spanish, etc.) (See application no. 5.) The student intercom and audio-active headset functions are turned off.

\section{APPLICATION 2}

\section{Functional Description}

Instructor or speaker(s) speak through the console microphone to students in the student positions as in application no. 1. Individual students interpret into live microphones. The interpretation can be monitored by the instructor and/or other students. (Disadvantage : mixing)

\section{Technical Description}

A second built-in mode in this type of language laboratory is the full intercom function referred to above. The instructor may speak through the intercom to all students at once, or to individuals or groups of students. Student positions use an open mike function in which their headsets are audio-active and they hear both the «input» (voice or tapes) and their own interpretation. By depressing the « listen $\gg$ switch for the individual student positions. The instructor can monitor the student's interpretation and make appropriate comments. The resultant mixing of the original utterance and the feedback from the student's interpretation may be disconcerting at first, but may be controlled satisfactorily by adjusting volume controls at the console and in the individual positions.

\section{APPLICATION 3}

\section{Functional Description}

Instructor or speaker(s) address students from the console without using the console microphone. The console microphone is brought to one of the positions in the first row of student positions. A student interpreter seated in front of this microphone interprets live utterances for other students listening through the system. Listeners may listen to the original utterance through the airways or to the interpretation through headsets connected to the system. Under certain circumstances, this arrangement may be used as a « working » system.

\section{Technical Description}

In order to more closely simulate a real conference situation, the following restructuring is used in the language lab. An extension cable is added to the instructor's console microphone, allowing it to be moved to a position in the first row of student positions. While the instructor or other speaker addresses the class without microphone, the student seated in front of the console microphone in the first row interprets directly into the console microphone. The console may be switched either to « all call» or "group» in order to channel the interpreter's voice to persons listening through headsets. 


\section{APPLICATION 4}

\section{Functional Description}

An amplifier and headset are brought to a student position in the first row of student positions together with the console microphone as described under application no. 3. A separate microphone attached to the amplifier is brought to the console. The instructor or other speaker speaks into the amplifier microphone at the console. The utterance is relayed to the headset of the student interpreter in the first row, and the student interpreter interprets through the system as described in application no. 3 .

\section{Technical Description}

As a modification of application no. 3 (supra) a closed system of interpretation may be used to simulate conference conditions where the original speaker's voice is relayed to the interpreter electronically. To do this, an independent microphone and amplifier are installed between the front instructor's console and the student interpreter in the first row. This unit may be any one of a number of very common general purpose PA systems. Only a very low wattage is required, and output of the amplifier is fed directly, and solely, into a set of earphones. Some minor adaptations of the output may be required to reduce speaker level output to the comparatively small capacity of the headset. In actual operation, the « live » voice may originate at the console and speak directly into the independent microphone. The speaker may speak in a normal voice directly into the microphone. The independent amplifier and attached headset are located in the student position in the first row of student positions. The student interpreter thus has control over the independent amplifier, and may adjust it for listening comfort. The student interpreter speaks through the console microphone located in the same position. This console microphone is performing the same functions as described in application no. 3 .

\section{APPLICATION 5}

\section{Functional Description}

Tapes are played at the console. Students listen in the student positions and interpret into a dead microphone as in application no. 1.

\section{Technical Description}

As indicated previously, most language laboratory consoles common to elementary and high school installations had the capacity for 3-5 built-in tape decks, each of which could play pre-recorded tapes. Individual routing of the tapes is provided by various switching modes-either «Master Program», "Group Program $\gg$, or individual student position program selector switches. In addition, many lab systems have inputs for external program sources such as records, radio, or additional tape decks. 


\section{APPLICATION 6}

\section{Functional Description}

Students listen to tapes from the console as in application no. 5, and interpret into a live microphone. They may be monitored by the instructor at the console or by other students in other positions.

\section{Technical Description}

This function simply adds the audio-active feature of the lab to the student's headsets. However, it also enables the instructor to monitor the students's interpretation and to make comments via the intercom. This mode presents the same disadvantages noted for application no. 2 (supra).

\section{APPLICATION 7}

\section{Functional Description}

Students listen to tapes from the tape recorders in the student positions and interpret into a dead microphone.

\section{Technical Description}

Most language labs which with sufficient resources have a library function whereby the student checks out a pre-recorded tape and takes it to an individual position for practice or, in this case, individual training.

\section{APPLICATION 8}

\section{Functional Description}

Student listens to tape from console and interprets into system tape recorder at the student position. (Disadvantage : mixing)

\section{Technical Description}

Included in level 3 and 4 language lab instructional modes is the means of recording a mixed input at the student tape recorder. In this mode, the instructor's input and the student's response are both recorded on a tape located at the student position. This mode presents the disadvantages referred to in applications no. 2 and no. 6 (supra).

(Note : An additional possibility for advanced level 4 language labs should be mentioned here. On many console installations, at least one, and often two, tape decks were wired as play-record machines. This would allow an instructor to use the master tape decks to play a source tape to student booths, or allow him to record students' responses at the master console. In most of these systems, the record tape machine is placed in the $"$ record $\gg$ mode and input is directed to it by depressing the individual student's «listen » switch located on the console. This may be considered as a variant of application no. 8.) 


\section{APPLICATION 9}

\section{Functional Description}

Students listen to live utterance or tapes from the console and interpret into portable tape recorders or cassette recorders at the student positions.

\section{Technical Description}

This application is similar to application no. 8. However, it has the further advantage of avoiding mixing of the source tape or utterance and the interpretation. The source tape and the interpretation tape may be monitored with a specially designed headset as described below.

Several operational difficulties should be mentioned here. First, it is very important that equipment be in the best possible operating condition. Many of the 60 's language laboratories fall into disuse largely because of inadequate maintenance and development. Nothing interferes more with a student's work than unreliable technology. Secondly, in many labs it would be a good investment to purchase new and more comfortable headsets for interpreting students than those which are normally available. Considering the time that a trainee must spend wearing them, good headsets are a must. Thirdly, in running special cables such as those required for the independent microphone and amplifier in application no. 4, it is important that good wiring techniques be used to prevent visual and physical interference with a student's movement and vision. Overhead cable drops are easy and relatively inexpensive for addition to existing labs. For the student interpreter station located in the first row of student positions, it might be appropriate to remove the existing tape deck and install the independent amplifier directly in its place - thus freeing space and concealing the necessary wiring.

Further minor construction might be undertaken to provide sound-proof booths for the student positions. In order to provide realistic simulated conference conditions, partitions could be removed between alternate pairs of student positions. These alternate pairs would then be enclosed in semi-soundproof \& traveling booths $\gg$. This would provide booths for two interpreters similar to a working facility.

It might also be useful to rewire a stereo headset in order to allow the instructor to plug a separate program source into each earpiece. This makes it possible to hear the original utterance in one ear and the interpretation in the other, obviating the need for clutching one headset to one ear and a second headset to the other.

\section{SUMMARY}

Advantages of these Applications

1. Simulation of the simultaneous technique with electronically assisted simultaneous interpreting.

2. Monitoring of interpretations by instructor or by other students. 
3. Simultaneous training from and into several languages during a single class session.

4. Simulation of conference situations (applications no. 3 and no. 4).

Disadvantages of these Applications

1. Built-in feedback of the system (applications no. 2, no. 6, no. 8).

2. Physical arrangement of facilities : no booths.

3. No audience as in fully simulated facilities. 